\title{
Mergers \& acquisitions research: A bibliometric study of top strategy and international business journals, 1980-2010
}

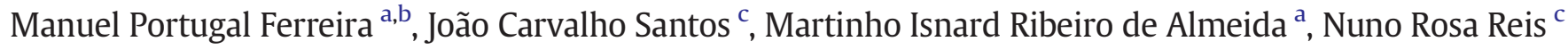 \\ a FEA-Universidade de São Paulo, São Paulo, SP, Brazil \\ b UNINOVE-Universidade Nove de Julho, Programa de Pós-Graduação em Administração, Av. Francisco Matarazzo, 612, Prédio C - 2º 05001-100 São Paulo, SP, Brazil \\ c School of Technology and Management, globADVANTAGE-Center of Research in International Business \&' Strategy, Polytechnic Institute of Leiria, Morro do Lena-Alto Vieiro, \\ Apartado 4163, 2411-901 Leiria, Portugal
}

\section{A R T I C L E I N F O}

\section{Article history:}

Received 10 October 2012

Received in revised form 11 March 2014

Accepted 13 March 2014

Available online 3 April 2014

\section{Keywords:}

Mergers \& acquisitions

Bibliometric study

Citations

Co-citations

Research themes

Review

\begin{abstract}
A B S T R A C T
Mergers and acquisitions (M\&As) are important modes through which firms carry out their domestic and international strategies and have been noted as the CEOs favorite strategy. As a significant field of study, M\&Aresearch has accumulated substantial knowledge. This bibliometric study examines the extant strategy and international business literature on M\&As. Methodologically, we examined a sample of 334 articles published in sixteen leading management/business journals, during a 31 year period - from 1980 to 2010. The results provide a global perspective of the field, identifying the works that have had the greater impact, the intellectual interconnections among authors and works, the main research traditions, or themes, delved upon on M\&Arelated research. Structural and longitudinal analyses reveal the changes in the intellectual structure of the field over time. A discussion on the accumulated knowledge and future research avenues concludes this paper.
\end{abstract} (c) 2014 Elsevier Inc. All rights reserved.

\section{Introduction}

Mergers and acquisitions (M\&As) are important vehicles for firms' business, product and geographic strategies. M\&As have become major strategic tools for multinational corporations' growth (Hitt, Harrison, \& Ireland, 2001), have significant impact on firms' performance (Laamanen \& Keil, 2008) and hold long-term consequences for the firm (Capron \& Pistre, 2002). Given its relevance, research on M\&As seems to have flourished and as the fields of study evolve and mature it is useful to periodically analyze the accumulated knowledge, its past directions and future challenges (Low \& MacMillan, 1988). This statement expresses our underlying contribution in complementing other reviews (Wan \& Yiu, 2009) and meta-analysis (Datta, Pinches, \& Narayanan, 1992; King, Dalton, Daily, \& Covin, 2004) on M\&A research.

In this bibliometric study we seek to better understand the extant knowledge on M\&A-related research in strategy and international business studies. Albeit there are multiple manners to conduct bibliometric research, we followed Ramos-Rodriguez and Ruiz-Navarro's (2004) procedures in their analysis of the intellectual structure of strategic management research, and Furrer, Thomas, and Goussevskaia's (2008) method to identify the themes researched. We conducted three

E-mail addresses: manuel.portugal@uninove.br (M.P. Ferreira), joao.santos@ipleiria.pt (J.C. Santos), martinho@usp.br (M.I.R. de Almeida), nuno.m.reis@ipleiria.pt (N.R. Reis). complementary analyses: a citation analysis to identify those works that have had the greatest impact on the field, as assessed by their citation frequency (Tahai \& Meyer, 1999). A co-citation analysis to identify connections among works, on the assumption that articles often cocited are likely to have an intellectual tie (Rehn \& Kronman, 2006; Shafique, 2013). And an analysis of the broad research themes delved into over the past three decades. The purpose is thus largely descriptive and aims at capturing a panoramic view of what was already written on the topic (Acedo, Barroso, \& Galan, 2006). Methodologically, we examined the articles on M\&As published in sixteen top tier business/ management journals (Harzing, 2011; Peng \& Zhou, 2006), in the period 1980 to 2010.

Our study contributes to better understand the stock of accumulated knowledge on M\&A-related research in the disciplines of strategic management and international business adding to existing reviews. While other studies have reviewed the developments in entire disciplines (Ramos-Rodriguez \& Ruiz-Navarro, 2004; Shafique, 2013) or specific topics (Acedo et al., 2006; King et al., 2004), this study is the first to apply bibliometric techniques and procedures to the study of M\&As within the context of IB and strategy. For instance, Datta et al.'s (1992) meta-analysis on M\&A research targeted at the factors that may drive wealth effects. King et al.'s (2004) meta-analysis of accounting and finance journals examined performance effects and concerned with identifying works measuring performance under different conditions and different types of performance in related and unrelated M\&As. Our 
study is markedly different, as we follow bibliometric techniques not meta-analyses, and includes a structural and a longitudinal component in uncovering what has been studied, higher impact works, intellectual ties binding works, and M\&A-related themes that have been examined. While it is perhaps partially true that a well-informed colleague may have a good grasp of this literature, knowledge is shared across academia by means of literature reviews, bibliometric studies and other forms of assessing what has been done. In fact, bibliometric studies have the advantage of escaping possible subjective biases of the researcher by treating statistically and mathematically (Diodato, 1994; Ramos-Rodriguez \& Ruiz-Navarro, 2004) the extant research.

Our results, using a sample of 334 articles identified, show how the topic has evolved. We identify Managing acquisitions: Creating value through corporate renewal by Haspeslagh and Jemison (1991) as the most relevant work - i.e. the most cited - and that the most relevant works in M\&A-related research are works focusing on the different aspects of M\&As. We also detected that no single theory has been dominant in M\&A research and we may indeed observe the contributions of four main theoretical strands: Agency theory, Institutional theory, Transaction cost theory and the Resource-based view (RBV). However, using a longitudinal perspective we may observe some intellectual changes such as the decrease in the use of financial theory and more management/business focus. Building on our findings, we identify several avenues for future research to deepen our understanding on M\&As as a firm strategy for both domestic and international expansion.

\section{Literature review}

Bibliometric studies use the extant published research to examine and delve into the patterns and trends of what has been published, thus helping explore, organize and make some sense of the work that has been done in a certain discipline (Diodato, 1994; Ferreira, 2011) or subject of study. Other more classical tools to undertake a literature review may not yield an accurate view of the state of the art on the subject, albeit they may rely on a deeper examination of the content of each work published. Bibliometric studies rely on a quantitative analysis of written source documentation (such as academic articles, books, reports, theses and dissertations, new on the media) as a relatively objective method to examine part or the totality of a scholarly discipline (Diodato, 1994; Nerur, Rasheed, \& Natarajan, 2008; Ramos-Rodriguez \& Ruiz-Navarro, 2004; Shafique, 2013). While bibliometric methods may be complemented with experts' evaluations and perceptions (Peng \& Zhou, 2006; Ramos-Rodriguez \& Ruiz-Navarro, 2004) or meta-analyses (King et al., 2004) they are especially useful by avoiding subjectivity and supporting the analysis with quantifiable and observable data (Nerur et al., 2008) that may or may not confirm what scholars intuitively think they know. Bibliometric studies may also benefit from objective measures to understand the structure of scientific knowledge or of a community of scholars with specific fields or disciplines (Ramos-Rodriguez \& Ruiz-Navarro, 2004; Shafique, 2013; White \& McCain, 1998).

Given the fast pace of academic publication (see Anne-Will Harzing (2010) on publish or perish) it is increasingly unfeasible to keep track on all that is being published (MacRae, 1969). The overwhelming volume of new information, conceptual developments and data are the milieu in which bibliometry becomes useful for providing a structured analysis to a large body of information, to infer trends over time, themes researched, identify shifts in the boundaries of the disciplines, detect most prolific scholars and institutions, and show the "big picture" of extant research. These studies may make visible what would otherwise remain 'invisible colleges' (Crane, 1972). Moreover, longitudinal bibliometric analysis covering a long period of time helps us better understand the most influential works, ideas, scholars and schools of thought, and topics (Nerur et al., 2008).
Bibliometric studies have already been published in other areas and sub-areas of management to inquire about the types of papers published, their authors, time lag from initial submission to publication, types of papers (empirical or theoretical) and the citations (Phelan, Ferreira, \& Salvador, 2002). Using bibliometry scholars have researched emerging topics, recent developments in a field (Shafique, 2013), main authors (Willett, 2007) and the impact of a scholar (Ferreira, 2011). The importance of different journals has also been examined in bibliometric studies (e.g., Baumgartner \& Pieters, 2003) whereas other studies preferred to focus on the affiliation of authors (Podsakoff, MacKenzie, Podsakoff, \& Bacharach, 2008) or the intellectual structure of a field (Ramos-Rodriguez \& Ruiz-Navarro, 2004; Rehn \& Kronman, 2006).

\section{Method}

\subsection{Sample}

We conducted a bibliometric study to assess the extant research on M\&As. To collect a representative sample of M\&A-related studies we selected the top sixteen journals publishing strategy and international business studies. We selected the journals using Anne-Will Harzing's (2011) rankings, the journals' impact factors, and prior studies that used a similar set or several of these journals (Datta et al., 1992; King et al., 2004; Peng \& Zhou, 2006; Podsakoff et al., 2008; Shafique, 2013). Hence, our sample was retrieved from the journals shown in Table 1 . We also delimited the observation period to 31 years, from 1980 to 2010 .

The empirical data was retrieved from the ISI Web of Knowledge by searching in the sixteen journals, in the search option 'topic', for the keywords: mergers \& acquisitions, mergers and acquisitions, M\&A, mergers, acquisitions, and consolidation \& merger of corporations. This double filtering of journals and keywords has the advantages of restricting the focus to management/business research journals and of assuring that our sample truly comprises M\&A-related articles. We further read the title and abstract of all articles published in the selected journals, from 1980 to 2010, to guarantee that the sample was complete.

During the period 1980 to 2010, these journals published 16,302 articles, 334 dealing with M\&As (Table 1). Using the software Bibexcel, we retrieved all bibliometric information of these 334 articles, such as the journal name, article title, authors, keywords and year. We further collected citation and co-citation data for each article. Then, manually, we normalized the authors' names and works, and corrected for different editions of books. The data was analyzed with Bibexcel, and the networks were drawn using the social networks' software Ucinet.

\subsection{Procedures}

Our study entailed three different and complementary procedures: citation and co-citation analyses and the research themes. The analyses comprise both a structural and a longitudinal component.

\subsection{Citation analysis}

A reference, or citation, is the acknowledgement that a paper gives to a previously published work. The scientific norm stipulates that scholars cite existing works when constructing their own work. These bibliographic references identify prior scholars, ideas, theories, methods or findings that inspired or were drawn upon when conducting the focal research. As put forth by Kochen (1987), a citation is an explicit recognition of an intellectual debt, and Martyn (1975) noted that it implies a tie between the citing and the cited works. Academic papers are embedded in a larger literature and do not stand alone (Ziman, 1968). Smith (1981, 87-79) stipulated four assumptions in citations: (1) citation of a work implies use of that work by the citing scholar, (2) citation of a work reflects the quality, significance and 
Table 1

Journals and sample.

\begin{tabular}{|c|c|c|c|c|c|c|}
\hline Years available in ISI & Journal & & Impact factor (1) & Total citations (2) & Total published (3) & Sample \\
\hline 1958-2011 & AMJ & Academy of Management Journal & 5.250 & 142,467 & 2902 & 14 \\
\hline $1956-2011$ & ASQ & Administrative Science Quarterly & 3.684 & 139,636 & 3399 & 9 \\
\hline 2000-2010 & CGIR & Corporate Governance: An International Review & 2.753 & 2775 & 634 & 12 \\
\hline 1956-2006 & $\mathrm{JB}$ & Journal of Business & n.a. & 38,682 & 2639 & 25 \\
\hline $1973-2011$ & JBR & Journal of Business Research & 1.773 & 27,099 & 2845 & 21 \\
\hline 1976-2011 & JIBS & Journal of International Business Studies & 4.184 & 40,120 & 1761 & 21 \\
\hline 1983-2011 & JM & Journal of Management & 3.743 & 47,856 & 1241 & 24 \\
\hline 1966-2011 & JMS & Journal of Management Studies & 3.817 & 30,694 & 2858 & 23 \\
\hline $1991-2011$ & LRP & Long Range Planning & 1.727 & 13,192 & 4006 & 28 \\
\hline 1991-2010 & MS & Management Science & 2.221 & 182,270 & 5592 & 12 \\
\hline $1992-2011$ & OS & Organization Science & 2.339 & 48,670 & 941 & 17 \\
\hline 1981-2011 & OSt & Organization Studies & 0.882 & 22,011 & 2066 & 14 \\
\hline 1990-2011 & SMJ & Strategic Management Journal & 3.583 & 120,413 & 1828 & 74 \\
\hline 1995-2011 & JEMS & Journal of Economics \& Management Strategy & 1.123 & 4730 & 466 & 21 \\
\hline 1997-2011 & JWB & Journal of World Business & 1.986 & 5260 & 432 & 10 \\
\hline 1994-2010 & TASM & Technology Analysis \& Strategic Management & 1.040 & 4039 & 683 & 9 \\
\hline
\end{tabular}

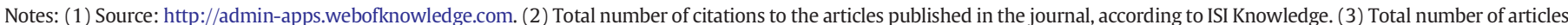
published in the journal, from founding up to 2010.

impact of that work, (3) scholars cite the best possible works, and (4) a cited work is related in content to the citing work. We performed a citation analysis to identify the works that have had the greatest impact, we also conducted a longitudinal analysis to detect research shifts.

\subsection{Co-citation analysis}

Co-citation analysis entails counting the frequency a selected pair of works is cited together in articles published (White \& McCain, 1998). Co-citation analysis identifies influential works and their interrelationships. This analysis provides an overview of the intellectual structure of a field of study (Shafique, 2013).

The third procedure involved identifying research themes on M\&As. Identifying themes often entails a subjective content analysis of a set of papers either manually, reading the papers, or using specialized software. We followed the procedure exposed in Furrer et al. (2008) and Ferreira (2011) and coded the author-supplied keywords into major categories, or themes. The author-supplied keywords reflect the content of each article since authors select the keywords that best signal its content to potentially readers and for indexing purposes.

Of the 334 articles, 310 contained keywords and only those were treated. The coding was needed since there were a large number of author-supplied keywords (608 different keywords) and examining such large number, many of which used only once, did not render interpretable results. Two coders classified each keyword into one of the 19 major themes: 'Performance', 'Environmental modeling: governmental, social, and political influences on strategy', 'Diversification and corporate strategy', 'Resource based view (RBV) and capabilities of the firm', 'Methodologies, theories and research issues', 'Learning and knowledge', 'R\&D, technology innovation', 'Financial theory', 'Culture, Organization and structure', 'Agency theory', 'Institutional theory', 'Corporate partnership', 'CEOs and top management teams (TMT)', 'Restructuring', 'Integration issues', 'Corporate governance', 'Entry modes and international strategy' (list available from the authors). While Furrer et al. (2008) classified 26 themes, they examined the entire discipline and we made some adjustments to better fit both the topic (M\&As) and the two disciplines. With this procedure we gained a clearer image of the subjects covered in the articles. Moreover, while prior studies classified each article into one category (see Furrer et al., 2008) we permit an article to be in more than one theme to acknowledge the multidimensional nature of academic research. For instance, an article may be classified as to the method, the theory and the object of study, according to the author-supplied keywords included.

\section{Results}

M\&A research has been growing steadily over the past three decades. Fig. 1 shows the evolution in the number of papers published on M\&As in the 16 journals scrutinized. Although there is an upwards trend, evidence shows that research on M\&As is rather scarce, consistently below $3 \%$ of the total articles published.

\subsection{Citation analysis}

The works that are more often cited are likely to be recognized has holding the greatest impact on a field of study, if we take citation frequency as a measure of impact (Ferreira, 2011). Jointly, the 334 articles in the sample used a total of 19,239 references. Examining such large list would be unfeasible and Table 2 shows the 20 most cited works by the 334 articles. The book Managing acquisitions: Creating value through corporate renewal, by Haspeslagh and Jemison (1991), had 74 citations, followed by the article by Jemison and Sitkin (1986) with 73 citations and Lubatkin's (1987) paper on mergers' strategies, ranking third, with 63 citations.

The two most cited works are related in dealing with process issues' post-acquisition. Both works follow an RBV/capabilities view with authors examining hazards involving capability transfer and the need to manage effectively the integration. For instance, Haspeslagh and Jemison (1991) delved on the need for cooperation for value creation post-acquisition and into some hazards that may emerge before the acquisition is completed.

To understand shifts in the field, how M\&As have been dealt with and the theories employed, we conducted a longitudinal analysis by splitting the sample in three ten-year periods: 1981-1990, 1991-2000 and 2001-2010. Table 3 highlights the 30 most cited works in each period.

The data on Table 3 allows some observations on the changes in the theoretical emphasis. The distinguishable pattern is the gradual move from a more traditional perspective, with an economic lens and applications of the transaction cost theory, to the RBV and its variant knowledge- and capability-based views and learning (e.g., Haleblian \& Finkelstein, 1999; Vermeulen \& Barkema, 2001).

A more detailed analysis reveals other distinctions. In the first period, the articles cited are mostly prescriptive (Paine \& Power, 1984) and supported on financial theories (Jensen, 1976; Lubatkin, 1983), economic theories (Rumelt, 1974), institutional theory (Williamson, 1975) and resource dependence (Pfeffer \& Salancik, 1978). In the second period (1991-2000), there is an emphasis on performance effects, 


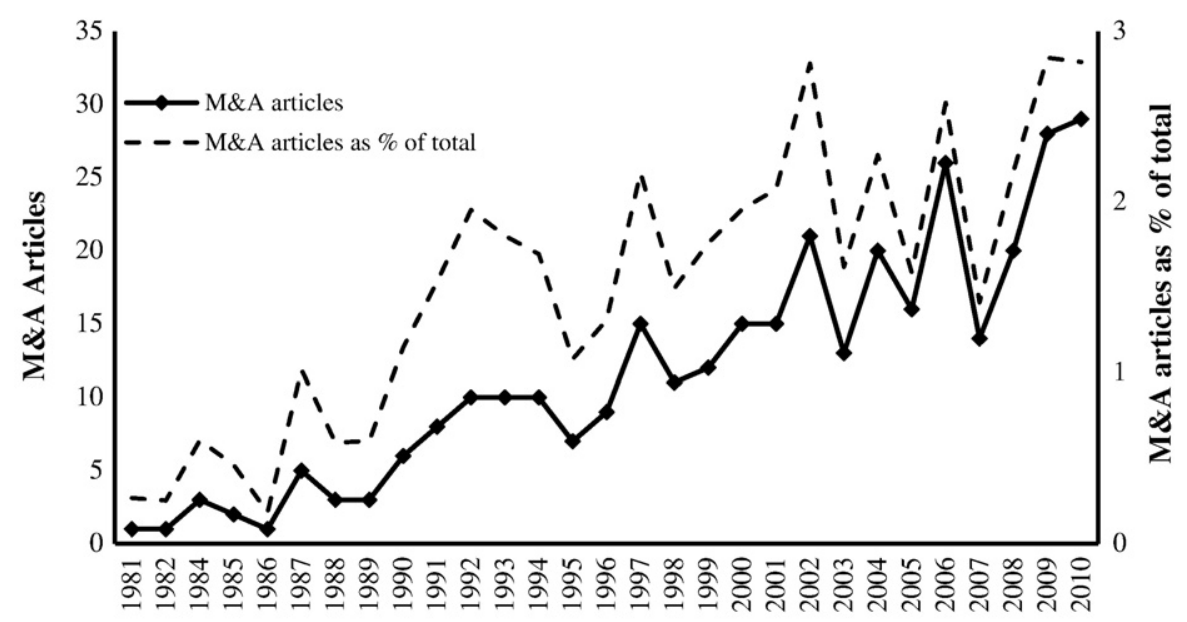

Note: The dotted line depicts the percentage of M\&A articles on the total number of articles published in the journals.

Source: Data collected from ISI Web of Knowledge.

Fig. 1. Evolution of articles published on M\&As: 1980-2010.

using financial theory (e.g., Lubatkin, 1987) and transaction cost theory (Chatterjee, 1986; Williamson, 1975). The third period (2001-2010) is marked by the rise of the resource-based view, knowledge and capabilities (Barney, 1988, 1991; Penrose, 1959). The citations also reveal an emphasis on organizational learning (Cohen \& Levinthal, 1990; Gammelgaard, 2004; Haleblian \& Finkelstein, 1999) and cultural issues (Chatterjee, 1992; Hofstede, 1980), which denote the study of outcomes and problems in post-M\&A integration.

\subsection{Co-citation analysis}

Fig. 2 presents the intellectual structure of the field, using the 30 most cited references in the 334 articles of the sample. The co-citation links, represented in the figure by the lines, correspond to the intellectual ties between the works. In reading the figure, the thickness of the line connecting a pair of works represents the strength of the tie; measured by the co-citation frequency. Moreover, the software places the works

Table 2

Most cited works on M\&A research.

Source: Data collected from ISI Web of Knowledge.

\begin{tabular}{lll}
\hline$\#$ & Reference & \# cit. \\
\hline 1 & Haspeslagh and Jemison (1991) & 74 \\
2 & Jemison and Sitkin (1986) & 73 \\
3 & Lubatkin (1987) & 63 \\
4 & Chatterjee (1992) & 63 \\
5 & Jensen (1983) & 60 \\
6 & Lubatkin (1983) & 58 \\
7 & Chatterjee (1986) & 57 \\
8 & Singh and Montgomery (1987) & 56 \\
9 & Walsh (1988) & 55 \\
10 & Porter (1987) & 51 \\
11 & Rumelt (1974) & 50 \\
12 & Amihud and Lev (1981) & 49 \\
13 & Seth (1990b) & 49 \\
14 & Roll (1986) & 46 \\
15 & Jensen (1986) & 45 \\
16 & Williamson (1975) & 44 \\
17 & Datta (1991) & 44 \\
18 & Ravenscraft and Scherer (1987) & 43 \\
19 & Morck, Shleifer, and Vishny (1990) & 42 \\
20 & Nahavandi and Malekzadeh (1988) & 42 \\
\hline
\end{tabular}

Note: \# citation is the absolute citation frequency. in a relative space within a circle such that works closer to the center occupy a more central position in the network, while at the periphery are works that although relevant have a relatively lower impact.

The more central works are Haspeslagh and Jemison (1991), Jemison and Sitkin (1986) and Lubatkin (1987), which makes them arguably the three most relevant works. A stronger tie is found linking Haspeslagh and Jemison (1991) with Chatterjee (1992) and Jensen (1983) with Rumelt (1974). The central group of works in the network captures scholars' core concerns. Haspeslagh and Jemison (1991) sought to understand the $M \& A$ process itself as a means to create value focusing especially on post-M\&A integration issues. Lubatkin (1987) focused the role of business relatedness on stockholders' value creation by M\&As. Clearly, at the core of the co-citation network is the concern with performance following M\&As.

\subsection{Research themes}

The third analysis involved observing the research themes delved upon (Fig. 3). The interpretation of the figure is similar to that of the co-citations. The diameter of the circles represents frequency (summing the author-supplied keywords): a larger circle indicates a theme more often researched. The thickness of the line reflects the strength of the relation between themes, such that the thicker the line the stronger the relation between two themes. For instance, 'performance' and 'corporate partnership' have a strong tie because a large number of articles on 'corporate partnership' also focus on 'performance' issues. Similarly, there is a strong tie connecting 'culture' and 'integration issues' revealing the scholarly emphasis on the post-acquisition hazards emerging from cultural differences and the difficulties in integrating firms.

Fig. 3 highlights the centrality of three themes: 'corporate partnership', 'performance' and 'environmental modeling: governmental, social, and political influences on strategy'. These are at the core of the network which is not surprising since when studying M\&As a primary concern lies on the performance impact of the M\&A deals on both acquirer and acquired firms. Managers often invoke performance improvements and capturing synergies while leveraging existing resources to justify M\&As.

While in Fig. 3 we grasp a perspective on the structure of the field, Fig. 4 depicts a longitudinal analysis showing shifts over time. Starting in 1991, the year keywords were made available in ISI Web of Knowledge, we split the sample in five year periods to identify the main research themes per period. For instance, the theme "corporate 
Table 3

Longitudinal analysis: The most cited references, by decade.

Source: Data collected from ISI Web of Knowledge.

\begin{tabular}{|c|c|c|c|c|c|}
\hline \multicolumn{2}{|l|}{1981 to 1990} & \multicolumn{2}{|l|}{1991 to 2000} & \multicolumn{2}{|l|}{2001 to 2010} \\
\hline \multicolumn{2}{|l|}{$\mathrm{n}=25$} & \multicolumn{2}{|l|}{$\mathrm{n}=107$} & \multicolumn{2}{|l|}{$\mathrm{n}=202$} \\
\hline Reference & $\mathrm{C}$ & Reference & C & Reference & $\mathrm{C}$ \\
\hline Lubatkin (1983) & 12 & Jemison and Sitkin (1986) & 34 & Haspeslagh and Jemison (1991) & 46 \\
\hline Salter and Weinhold (1979) & 12 & Chatterjee (1986) & 31 & Haleblian and Finkelstein (1999) & 39 \\
\hline Jensen (1983) & 11 & Lubatkin (1987) & 29 & Larsson and Finkelstein (1999) & 38 \\
\hline Rumelt (1974) & 11 & Porter (1987) & 28 & Chatterjee (1992) & 37 \\
\hline Kitching (1967) & 10 & Haspeslagh and Jemison (1991) & 28 & Jemison and Sitkin (1986) & 33 \\
\hline Amihud and Lev (1981) & 9 & Singh and Montgomery (1987) & 27 & Walsh (1988) & 32 \\
\hline Chatterjee (1986) & 7 & Jensen (1983) & 26 & Hayward (2002) & 32 \\
\hline Halpern (1983) & 6 & Chatterjee (1992) & 26 & Lubatkin (1987) & 30 \\
\hline Williamson (1975) & 6 & Lubatkin (1983) & 25 & Seth (1990b) & 29 \\
\hline Mandelker (1974) & 6 & Rumelt (1974) & 23 & Buono and Bowditch (1989) & 29 \\
\hline Porter (1985) & 6 & Salter and Weinhold (1979) & 22 & Jensen (1986) & 29 \\
\hline Jemison and Sitkin (1986) & 6 & Ravenscraft and Scherer (1987) & 22 & Penrose (1959) & 28 \\
\hline Porter (1980) & 6 & Porter (1985) & 20 & Barney (1991) & 27 \\
\hline Bettis and Hall (1982) & 5 & Seth (1990b) & 20 & Datta (1991) & 27 \\
\hline Christensen and Montgomery (1981) & 5 & Nahavandi and Malekzadeh (1988) & 19 & Capron, Dussauge and Mitchell (1998) & 26 \\
\hline Asquith, Brunner and Mullins (1983) & 5 & Walsh (1988) & 19 & Cohen and Levinthal (1990) & 25 \\
\hline Lubatkin and Shrieves (1986) & 5 & Williamson (1975) & 18 & Singh and Montgomery (1987) & 25 \\
\hline Lewellen (1971) & 5 & Morck et al. (1990) & 18 & Roll (1986) & 25 \\
\hline Dodd (1980) & 5 & Amihud and Lev (1981) & 18 & Schweiger and DeNisi (1991) & 25 \\
\hline Fama (1980) & 5 & Roll (1986) & 17 & Hayward and Hambrick (1997) & 24 \\
\hline Pfeffer and Salancik (1978) & 5 & Datta (1991) & 17 & Morck, Shleifer, and Vishny (1990) & 24 \\
\hline Yip (1982) & 5 & Barney (1988) & 17 & Barney (1988) & 23 \\
\hline Porter (1987) & 4 & Jensen (1986) & 16 & Nahavandi and Malekzadeh (1988) & 23 \\
\hline Roll (1986) & 4 & Kitching (1967) & 15 & Hofstede (1980) & 23 \\
\hline Jensen (1976) & 4 & Kusewitt (1985) & 15 & Jensen (1983) & 23 \\
\hline Walsh (1988) & 4 & Shelton (1988) & 14 & Datta et al. (1992) & 23 \\
\hline Manne (1965) & 4 & Jarrell et al. (1988) & 14 & Amihud and Lev (1981) & 22 \\
\hline Parsons and Baumgartner (1970) & 4 & Jensen (1976) & 13 & Capron (1999) & 22 \\
\hline Paine and Power (1984) & 4 & Pfeffer and Salancik (1978) & 13 & Sirower (1997) & 22 \\
\hline Melicher and Rush (1974) & 4 & Trautwein (1990) & 13 & Nelson and Winter (1982) & 22 \\
\hline
\end{tabular}

Note: $\mathrm{n}$ is the number of articles. $\mathrm{C}$ is the citation frequency.

partnership' was the most researched followed by 'performance' across periods, while 'CEOs and Top Management Teams' seems to gradually fall off scholars' radar. Research based on 'environmental modeling: governmental, social, and political influences on strategy' is one of the top 5 research themes in 2001-2005 and 2006-2010, and 'RBV and capabilities of the firm' was more salient in the latter period, denoting a heightened interest on the impact of M\&As in reconfiguring firms' capabilities. Less often investigated have been themes such as restructuring, entry modes and international strategy, culture, organization and structure, agency theory and institutional theory.

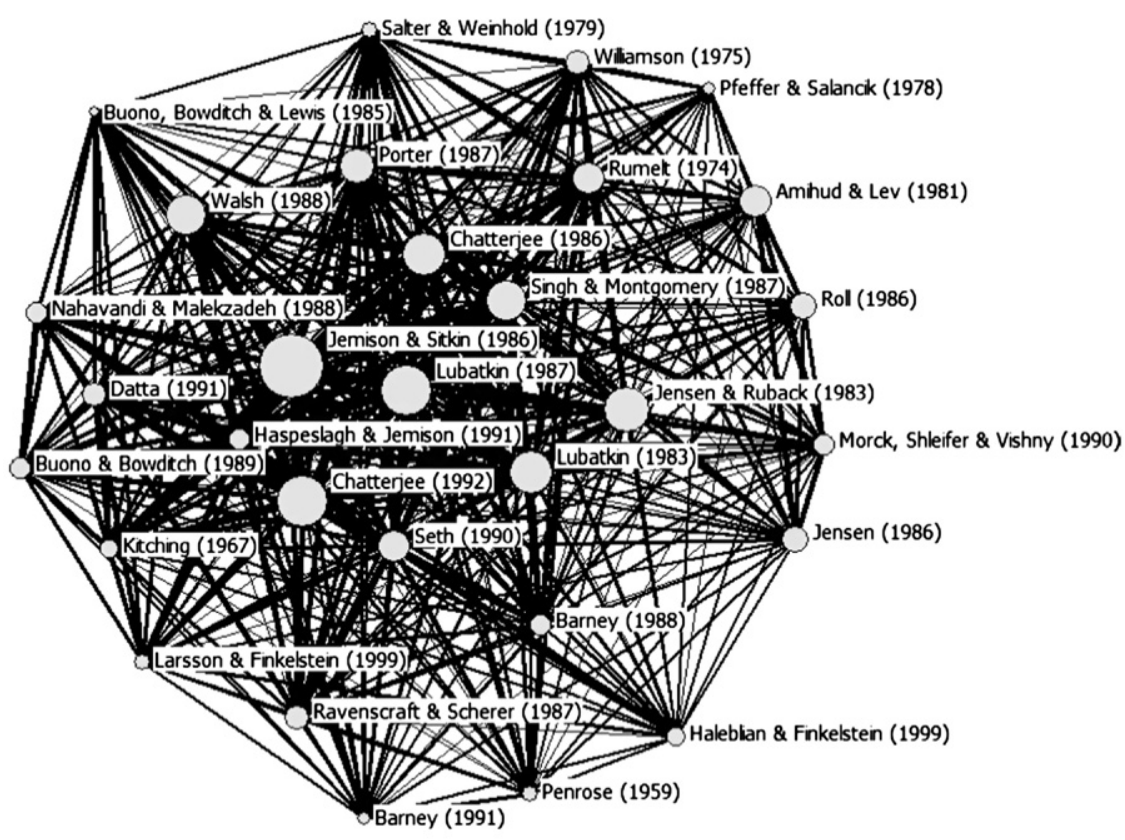

Source: Data collected from ISI Web of Knowledge.

Fig. 2. Co-citation network among the top 30 most cited articles. 


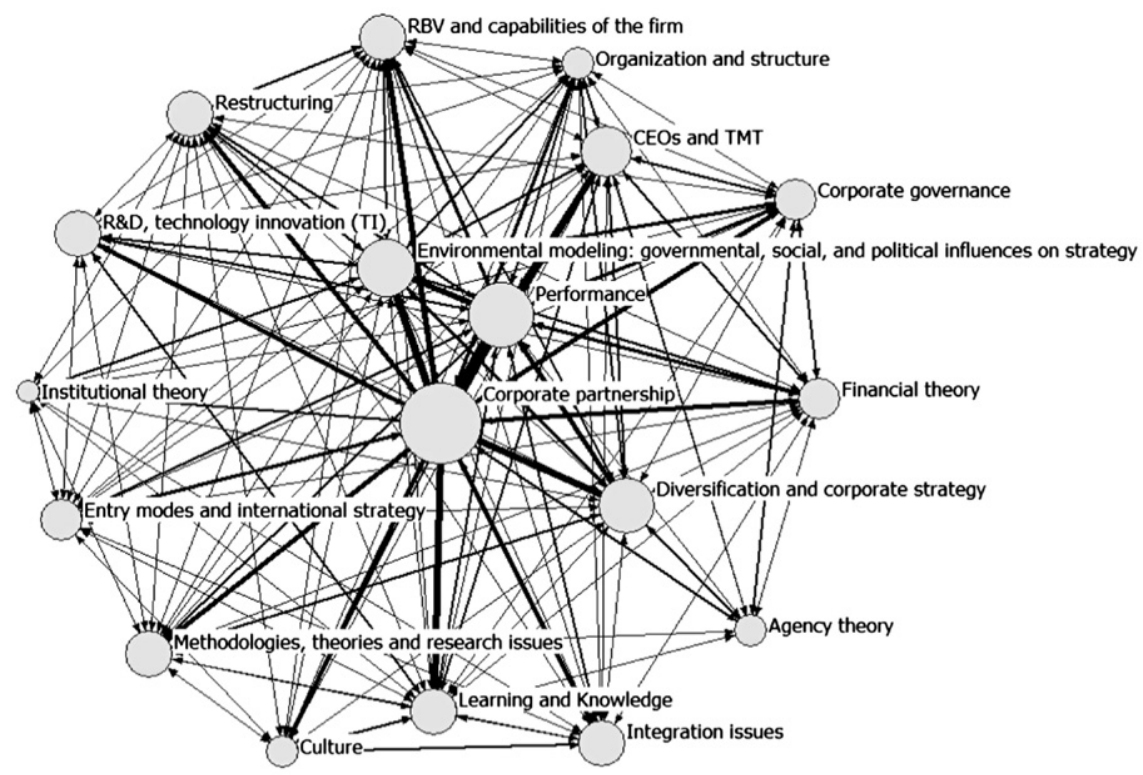

Note: author-supplied keywords are available only after 1991. Source: data collected using ISI Web of Knowledge

Fig. 3. Research themes.

\section{Discussion}

As firms continue to deploy M\&A strategies to expand scholars seem to be paying increased research attention. In this paper we analyzed the extant strategic management and international business research on M\&As, by conducting a bibliometric study of the articles published from 1980 to 2010 on M\&As in sixteen leading business/management journals. The procedures involved structural and longitudinal analyses of citations, co-citations and research themes delved into.

This study complements prior literature reviews and meta-analyses on M\&A research. This study is perhaps more useful for doctoral students and newcomers to the field that will find a systematization of the literature, the core works, the theories and how they are related. The analyses encompass a broad picture of the literature from which newcomers and doctoral students may endeavor in developing their own research agenda.

\subsection{What we already know}

There has been an extensive research on M\&As both from a domestic and an international standpoint and a majority of this research is classifiable in the domain of strategic management. Performance emerged as a major concern for much of the M\&A-related studies, with many studies focusing on pre- and post-acquisition performance (Capron \& Pistre, 2002; Laamanen \& Keil, 2008), with no clear consensus. Rao and Sanker (1997), for instance, found a positive effect on the liquidity, leverage and profitability of the acquirer. M\&As increase the efficiency and effectiveness of entire industries and impact individual companies' competitive ability (Hitt et al., 2001), holding a positive impact on firms' performance (Chatterjee, 1986, 1992). Other scholars found that M\&As either have no effect or are detrimental to firms' post-acquisition performance (e.g., Datta et al., 1992; Jarrell, Brickley, \& Netter, 1988; Singh \& Montgomery, 1987). M\&As may have a negative impact on firms' post-acquisition performance due to poor target selection, lack of synergies, inadequate integration of the acquired (Hitt et al., 2001), cultural differences (Child, Faulkner, \& Pitkethly, 2001), and excessive debt resulting from the acquisition effort (Haspeslagh \& Jemison, 1991; Hitt et al., 2001). In sum, M\&As' impact on firms' performance is not conclusive. Extant research on post-acquisition integration has also emphasized cultural hazards in integrating across different national and organizational cultures (Child et al., 2001; Haspeslagh \& Jemison, 1991; Jemison \& Sitkin, 1986), the impact of resource relatedness (Chatterjee, 1986; Chatterjee, Lubatkin, Schweiger, \& Weber, 1992; Lubatkin, 1987; Seth, 1990b), the loss of value post-acquisition (Dyer,
1991-1995

1. Corporate partnership (11)

2. Performance (4)

3. CEOs and TMT (4)

4. Financial theory (3)

5. Integration issues (3)
1996-2000

1. Corporate partnership (16)

2. Diversification and corporate strategy (9)

3. Performance (6)

4. CEOs and TMT (6)

5. Resource based view (RBV) and capabilities of the firm (5)
2001-2005

1. Corporate partnership (27)

2. Performance (12)

3. Diversification and corporate strategy $(9)$

4. Methodologies, theories and research issues $(9)$

5. Environmental modeling: governmental, social, and political influences on strategy (8)
2006-2010

1. Corporate partnership (67)
2. Performance (34)
3. Environmental modeling:
governmental, social, and
political influences on
strategy (27)
4. Corporate Governance (15)
5. Resource based view
(RBV) and capabilities of
the firm (14)

Note: author-supplied keywords are available only after 1991.

Source: data collected from ISI Web of Knowledge

Fig. 4. Top research themes by period. 
Kale, \& Singh, 2004) and the target selection (Haspeslagh \& Jemison, 1991).

A stream of research has used transaction cost theory (TCT) in explaining M\&As. In IB studies this perspective has led to explaining the choice between alternative foreign entry modes (Dyer et al., 2004; Harzing, 2002; Kale, Singh, \& Raman, 2009). Following Hennart and Park (1993) greenfield ventures were incur in lower transaction costs than M\&As because greenfield operations avoid the costs of retraining the workforce and the integration hazarding involved in merging different organizational cultures. M\&As provide more opportunities for greater organizational efficiencies than alternative foreign entry modes (Harzing, 2002; Hennart \& Park, 1993; Yip, 1982). Notwithstanding these important contributions, our data shows a relative decrease in the use of TCT on M\&A research.

An increasing part of the current research is supported on the resource-, capabilities- or knowledge-based views of the firm. M\&As are vehicles used by acquirers to learn and augment their knowledge base, resources and capabilities (Ferreira, 2007), especially for acquiring resources and knowledge that are not available in the factor market (Barney, 1986; Ferreira, 2007). Hence, this stream of research on M\&As as opportunities for firms to reconfigure their businesses and alter their pool of resources and capabilities (Ferreira, 2007; Karim \& Mitchell, 2000) has made significant inroads in clarifying the potential gains accruing from $M \& A s$ beyond financial or economic performance.

Extant research has also established a set of motives driving firms to acquire. Bradley, Desai, and Kim (1988), Seth (1990a) and Seth, Song, and Pettit (2000) suggested that a major driver of M\&As is exploiting synergies between the firms' value chains that would not be captured otherwise. These synergies may seek greater operational efficiency and increased market power (Seth, 1990a; Singh \& Montgomery, 1987), reduce competition (Bradley et al., 1988), decrease dependency on a set of consumers (Chatterjee, 1986), the ability to increase prices for consumers (Hitt, Hoskisson, \& Ireland, 1990), benefit from cost reductions and economies of scale (Homburg \& Bucerius, 2006) or an effective coordination of resources (Chatterjee \& Lubatkin, 1990). Brouthers and Brouthers (2000) noted M\&As as a vehicle for overcoming the shortcomings of financial markets. Chatterjee and Lubatkin (1990) suggested M\&As as a manner of restructuring poorly managed companies, and Barney $(1986,1991)$ that M\&As are modes for accessing or controlling valuable resources, not imitable and indispensable to achieve a competitive advantage.

\subsection{Future research paths}

Advancing future research avenues comprises subjective views of what may be interesting and where are current knowledge gaps. Additional research is warranted in constructing a better understanding why firms acquire given the evidence of potential losses, the influence of the surrounding milieu in the decision to acquire and in completing the acquisition, the impact of the institutional environment in M\&As, the role of government intervention on firms' decisions to expand through acquisitions, and so forth.

The manner in which managers chose their targets is ill understood. On occasion, the acquirer managers disregard errs in assessing the value of a target firm and continue the deal (Roll, 1986). The managerial or hubris hypothesis (Hayward \& Hambrick, 1997) contrasts with the assumption that managers are economically rational when deciding to pursue an M\&A. Managers may undertake M\&As to maximize their own utility at the expense of the shareholders (Seth et al., 2000). However, it is less known how a number of barriers - barriers found in the cultural differences, organizational politics and managers' bounded rationality - may lead to suboptimal choices of which firms to acquire, misestimating the potential synergies and the economic value of the M\&A. For instance, in the context of emerging markets, the race to capture a position in the market may lead firms to acquire. A study by Kale et al. (2009) noted that in certain instances emerging multinational may be better off not pursuing to integrate acquired and acquiring firms' post-acquisition to maintain their identity and capabilities.

We highlighted the growing use of resource-, capabilities- and knowledge-based approaches (Barney, 1991; Penrose, 1959) for studying M\&As. Our data revealed that M\&A research has evolved from the original work on the diversification strategies (Rumelt, 1974) to a focus on figuring out when are M\&As beneficial for firms (Barney, 1988; Capron, Dussauge, \& Mitchell, 1998; Larsson \& Finkelstein, 1999; Lubatkin, 1983) and to a perspective on firms' advantages based on the resources held (Barney, 1986, 1991; Wernerfelt, 1984). Scrutinizing M\&As as modes to access resources not yet held (Ferreira, 2007; Karim \& Mitchell, 2000; Vermeulen \& Barkema, 2001), we should measure the target firms' unique employee skills, organizational technologies and knowledge and if an acquisition is required to access them (Gammelgaard, 2004), or whether to partner would suffice (Dyer et al., 2004; Kale et al., 2009).

Hence, future research needs to assess the true resource-, capabilitybuilding potential from acquisitions (Ferreira, 2007). Much of the extant research fails to capture learning effects (Collins, Holcomb, Certo, Hitt, \& Lester, 2009) or how much firms' capabilities augmented and rather treats the access to resources not held - firm, regional or national level - to infer that learning occurs. That is, received wisdom has really dealt with the access to critical resources rather than actual learning. Conceptually, a learning perspective whereby M\&As are taken as learning options (Cohen \& Levinthal, 1990; Ferreira, 2007; Gammelgaard, 2004; Vermeulen \& Barkema, 2001) that contribute to developing capabilities through M\&As is interesting. But what does the actual practice by firms show? Future studies need to assess whether learning from a target firm and building new capabilities is a real reason for why firms acquire (Gammelgaard, 2004; Haleblian \& Finkelstein, 1999). A study by Ferreira (2005) on a sample of US multinationals showed that M\&As tend to occur to relatively proximate technological spaces, without much diversification from the core business. Even experienced multinationals tended to diversify relatively little from their prior experiences, revealing that the learning potential would not be great.

Institutional theory has been remarkably absent from M\&A research, probably because a majority of FDI originates in developed countries, with established, sophisticated and stable institutions (Peng, Sun, Pinkham, \& Chen, 2009). However, the institutional context of acquirer and acquired firms may matter and firms may be reluctant to undertake acquisitions in weak institutional environments. Future research may explore the institution-based view examining the role of the home country environment (Pablo, 2009) and governments for emerging multinationals undertaking M\&As abroad (Peng et al., 2009). Some of the facets of governmental intervention comprise direct support to FDI operations, low interest financing, taxation, facilitating expatriations, content requirements, and an array of different concessions that are likely to influence firms' decisions. On a similar stream, emerging multinationals may engage in M\&As when entering foreign countries to gain access to natural resources, build reputation by controlling worldwide known brands, and managerial hubris (Hayward \& Hambrick, 1997; Roll, 1986; Peng, 2012). This third motivation might be a fertile ground to deepen research on governance (Desai, Kroll, \& Wright, 2005; Globerman, Peng, \& Shapiro, 2011) involving M\&As from emerging economies. It is worth noting that many emerging multinationals are state-owned, or subject to state intervention, and national pride or political interests may drive expansion through acquiring foreign flagship firms.

\subsection{Limitations}

There are limitations to this study. First, albeit our research design included sampling from sixteen top business journals, these are a subset of all journals and of all works published on M\&As. Other journals also publish M\&A research, such as disciplinary journals in Economics and 
Finance. However, research on economics and finance tends to be quite hermetic and arguably seeks little contribution outside the core discipline (Schäffer, Nevries, Fikus, \& Meyer, 2011). There are also lower status or less commonly available journals that also publish M\&A-related research and other source documents. Moreover, the journals selected fit two criteria: these journals are usually available in the databases subscribed by the universities; and, these journals are among the leading journals in management and for publishing strategic management and international business studies. As leading journals it is reasonable to suggest that they are more likely to attract scholars publishing high quality research and will probably reflect the current topics of scholarly interest. In journal selection we already have a variety of perspectives. For instance, JE\&MS incorporates more often economic theory in strategic decisions; LRP seems to publish relatively more case-based research, and JIBS publishes articles with an international orientation. Hence, we are confident that the articles collected are representative sample of the research in the two disciplines. Nonetheless, future studies may extend the number of journals sampled and prospect into how different disciplines research M\&As and what are the issues delved into.

In identifying research themes we did not undertake an in-depth content analysis of the papers. While our method of using the authorsupplied keywords to infer content seems reasonable, it is just a proxy that does not preclude the complete reading of the papers to unveil the intellectual structure of the field. Other forms of content analysis may be able to explore in greater depth the theories used and the research questions. Such analyses may provide additional understanding of how research on M\&As has evolved and detect additional gaps.

\section{Concluding remarks}

This study provided a quantitative analysis of the extant literature on M\&As that complements prior literature reviews. To obtain a broad view of the field, we identified the most cited works, arguably those most influent, for M\&A research and how they are intellectually interconnected. We delved into the themes researched and their relational ties. The analyses provide researchers with a view on what is already known but we also advance several avenues for future research.

$M \& A$ research still warrants additional research as the CEOs' preferred strategy. As firms continue to deploy M\&As to expand business and geographic scope, the academia and practitioners must fully understand the impact, the costs and benefits of engaging in M\&As. M\&As are costly and risky ventures and poorly designed M\&A deals may lead firms to big losses. Hence, there abounds space for additional research in multiple national and international settings.

\section{References}

Acedo, F., Barroso, C., \& Galan, J. (2006). The resource-based theory: Dissemination and main trends. Strategic Management Journal, 27(7), 621-636.

Amihud, Y., \& Lev, B. (1981). Risk reduction as a managerial motive for conglomerate mergers: A transaction cost analysis. Bell Journal of Economics, 12(2), 605-616.

Asquith, P., Bruner, R., \& Mullins, D., Jr (1983). The gains to bidding firms from merger. Journal of Financial Economics, 11(1), 121-139.

Barney, J. (1986). Strategic factor markets: Expectations, luck, and business strategy. Management Science, 32(10), 1231-1241.

Barney, J. (1988). Returns to bidding firms in mergers and acquisitions: Reconsidering the relatedness hypothesis. Strategic Management Journal, 9(SI), 71-78.

Barney, J. (1991). Firm resources and sustained competitive advantage. Journal of Management, 17(1), 99-120.

Baumgartner, H., \& Pieters, R. (2003). The structural influence of marketing journals: A citation analysis of the discipline and its subareas over time. Journal of Marketing, 67(2), 123-139.

Bettis, R., \& Hall, W. (1982). Diversification strategy, accounting determined risk, and accounting determined return. Academy of Management Journal, 25(2), 254-264.

Buono, A., \& Bowditch, J. (1989). The human side of mergers and acquisitions: Managing collisions between people, cultures, and organizations. San Francisco: Jossey-Bass.

Bradley, M., Desai, A., \& Kim, E. (1988). Synergistic gains from corporate acquisitions and their division between the stockholders of target and acquiring firms. Journal of Financial Economics, 21(1), 3-40.

Brouthers, K., \& Brouthers, L. (2000). Acquisition or greenfield start-up? Institutional, cultural and transaction cost influences. Strategic Management Journal, 21(1), 89-97.
Capron, L. (1999). The long-term performance of horizontal acquisitions. Strategic Management Journal, 20(11), 987-1018.

Capron, L., Dussauge, P., \& Mitchell, W. (1998). Resource redeployment following horizontal acquisitions in Europe and North America, 1988-1992. Strategic Management Journal, 19(7), 631-661.

Capron, L., \& Pistre, N. (2002). When do acquirers earn abnormal returns? Strategic Management Journal, 23(9), 781-794.

Chatterjee, S. (1986). Types of synergy and economic value: The impact of acquisition on merging and rival firms. Strategic Management Journal, 7(2), 119-139.

Chatterjee, S. (1992). Sources of value in takeovers: Synergy or restructuring implications for target and bidder firms. Strategic Management Journal, 13(4), 267-286.

Chatterjee, S., \& Lubatkin, M. (1990). Corporate mergers, stockholder diversification, and changes in systematic risk. Strategic Management Journal, 11(4), 255-268.

Chatterjee, S., Lubatkin, M., Schweiger, D., \& Weber, Y. (1992). Cultural differences and shareholder value in related mergers: Linking equity and human capital. Strategic Management Journal, 13(5), 319-334.

Child, J., Faulkner, D., \& Pitkethly, R. (2001). The management of international acquisitions: Realizing their potential value. New York: Oxford University Press.

Christensen, H., \& Montgomery, C. (1981). Corporate economic performance: Diversification strategy versus market structure. Strategic Management Journal, 2(4), 327-343.

Cohen, W., \& Levinthal, D. (1990). Absorptive capacity: A new perspective on learning and innovation. Administrative Science Quarterly, 35(1), 128-152.

Collins, J., Holcomb, T., Certo, S., Hitt, M., \& Lester, R. (2009). Learning by doing: Crossborder mergers and acquisitions. Journal of Business Research, 62(12), 1329-1334.

Crane, D. (1972). Invisible colleges: Diffusion of knowledge in scientific communities. Chicago: University of Chicago Press.

Datta, D. (1991). Organizational fit and acquisition performance: Effects of postacquisition integration. Strategic Management Journal, 12(4), 281-298.

Datta, D., Pinches, G., \& Narayanan, V. (1992). Factors influencing wealth creation from mergers and acquisitions: A meta-analysis. Strategic Management Journal, 13(1), $67-84$.

Desai, A., Kroll, M., \& Wright, P. (2005). Outside board monitoring and the economic outcomes of acquisitions: a test of the substitution hypothesis. Journal of Business Research, 58(7), 926-934.

Diodato, V. (1994). Dictionary of bibliometrics. Binghamton: Haworth Press

Dodd, P. (1980). Merger proposals, management discretion and stockholder wealth. Journal of Financial Economics, 8(2), 105-137.

Dyer, J., Kale, P., \& Singh, H. (2004). When to ally and when to acquire. Harvard Business Review, 82(6), 109-115.

Fama, E. (1980). Agency Problems and the Theory of the Firm. Journal of Political Economy, $88(2), 288-307$.

Ferreira, M. (2005). Building and leveraging knowledge capabilities through cross border acquisitions: The effect of the multination corporation's capabilities and knowledge strategy on the degree of equity ownership. Unpublished PhD dissertation: The University of Utah, USA.

Ferreira, M. (2007). Building and leveraging knowledge capabilities through cross-border acquisitions. In S. Tallman (Ed.), New Generations in International Strategy (pp. 162-179). Cheltenham: Edward Elgar Publishing, Ltd.

Ferreira, M. (2011). A bibliometric study on Ghoshal's managing across borders. Multinational Business Review, 19(4), 357-375.

Furrer, O., Thomas, H., \& Goussevskaia, A. (2008). The structure and evolution of the strategic management field: A content analysis of 26 years of strategic management research. International Journal of Management Reviews, 10(1), 1-23.

Gammelgaard, J. (2004). Access to competence: An emerging acquisition motive. European Business Forum, 5(1), 44-48.

Globerman, S., Peng, M., \& Shapiro, D. (2011). Corporate governance and Asian companies. Asia Pacific Journal of Management, 28(1), 1-14.

Haleblian, J., \& Finkelstein, S. (1999). The influence of organizational acquisition experience on acquisition performance: A behavioral learning perspective. Administrative Science Quarterly, 44(1), 29-56

Halpern, P. (1983). Corporate acquisitions: A theory of special cases? A review of event studies applied to acquisitions. Journal of Finance, 38(2), 297-317.

Harzing, A. (2002). Acquisitions versus Greenfield investments: International strategy and management of entry modes. Strategic Management Journal, 23(3), 211-227.

Harzing, A. (2010). The publish or perish book. Melbourne: Tarma Software Research.

Harzing, A. (2011). Journal quality list, 38th edition. Retrieved from. http://www.harzing. $\mathrm{com} / \mathrm{jql} . \mathrm{htm}$

Haspeslagh, P., \& Jemison, D. (1991). Managing acquisitions: Creating value through corporate renewal. New York: The Free Press.

Hayward, M. (2002). When do firms learn from their acquisition experience? Evidence from 1990 to 1995. Strategic Management Journal, 23(1), 21-39.

Hayward, M., \& Hambrick, D. (1997). Explaining the premiums paid for large acquisitions: Evidence of CEO Hubris. Administrative Science Quarterly, 42(1), 103-127.

Hennart, J. -F., \& Park, Y. (1993). Greenfield vs. acquisition: The strategy of Japanese investors in the United States. Management Science, 39(9), 1054-1070.

Hitt, M., Harrison, J., \& Ireland, R. (2001). Mergers and acquisitions: A guide to creating value for stakeholders. New York: Oxford University Press.

Hitt, M., Hoskisson, R., \& Ireland, R. (1990). Mergers and acquisitions and managerial commitment to innovation in M-forms. Strategic Management Journal, 11(SI), 29-47.

Hofstede, G. (1980). Culture's consequences: International differences in work-related values. Beverly Hills: Sage Publications.

Homburg, C., \& Bucerius, M. (2006). Is speed of integration really a success factor of mergers and acquisitions? An analysis of the role of internal and external relatedness. Strategic Management Journal, 27(4), 347-367. 
Jarrell, A., Brickley, J., \& Netter, J. (1988). The market for corporate control: The empirical evidence since 1980. Journal of Economic Perspectives, 2(1), 49-68.

Jemison, D., \& Sitkin, S. (1986). Corporate acquisitions: A process perspective. Academy of Management Review, 11(1), 145-163.

Jensen, M. (1976). A theory of the firm: Governance, residual claims and organizational forms. Journal of Financial Economics, 3(4), 305-360.

Jensen, M. (1983). Organization theory and methodology. The Accounting Review, 58(2), 319-339.

Jensen, M. (1986). The agency costs of free cash flow: Corporate finance and takeovers. American Economic Review, 76(2), 323-329.

Kale, P., Singh, H., \& Raman, A. (2009). Don't integrate your acquisitions, partner with them. Harvard Bus Rev, 87(12), 109-115.

Karim, S., \& Mitchell, W. (2000). Path-dependent and path-breaking change: Reconfiguring business resources following acquisitions in the U.S. medical sector, 1978-1995. Strategic Management Journal, 21(10-11), 1061-1081.

King, D., Dalton, D., Daily, C., \& Covin, J. (2004). Meta-analyses of post-acquisition performance: Indications of unidentified moderators. Strategic Management Journal, 25(2), 187-200.

Kitching, J. (1967). Why do mergers miscarry? Harvard Business Review, 45(6), 84-101.

Kochen, M. (1987). How well do we acknowledge intellectual debts? Journal of Documentation, 43(1), 54-64.

Kusewitt, J. (1985). An exploratory study of strategic acquisition factors relating to performance. Strategic Management Journal, 6(2), 151-169.

Laamanen, T., \& Keil, T. (2008). Performance of serial acquirers: Toward an acquisition program perspective. Strategic Management Journal, 29(6), 663-672.

Larsson, R., \& Finkelstein, S. (1999). Integrating strategic, organizational, and human resource perspectives on mergers and acquisitions: A case survey of synergy realization. Organization Science, 10(1), 1-26.

Lewellen, W. (1971). A pure financial rationale for the conglomerate merger. Journal of Finance, 26(2), 521-537.

Low, M., \& MacMillan, I. (1988). Entrepreneurship: Past research and future challenges. Journal of Management, 14(2), 139-161.

Lubatkin, M. (1983). Merger and the performance of the acquiring firm. Academy of Management Review, 8(2), 218-225.

Lubatkin, M. (1987). Merger strategies and stockholder value. Strategic Management Journal, 8(1), 39-53.

Lubatkin, M., \& Shrieves, R. (1986). Towards reconciliation of market performance measures to strategic management research. Academy of Management Review, 11(3), 497-512.

MacRae, D. (1969). Growth and decay curves in scientific citations. American Sociological Review, 34(5), 631-635.

Mandelker, G. (1974). Risk and return: The case of merging firms. Journal of Financial Economics, 1(4), 303-335.

Manne, H. (1965). Mergers and the market for corporate control. Journal of Political Economy, 73(2), 110-120.

Martyn, J. (1975). Citation analysis. Journal of Documentation, 31(4), 290-297.

Melicher, R., \& Rush, D. (1974). Evidence on the acquisition-related performance of conglomerate firms. Journal of Finance, 29(1), 141-149.

Morck, R., Shleifer, A., \& Vishny, R. (1990). Do managerial objectives drive bad acquisitions? Journal of Finance, 45(1), 31-48.

Nahavandi, A., \& Malekzadeh, A. (1988). Acculturation in mergers and acquisitions. Academy of Management Review, 13(1), 79-90.

Nelson, R., \& Winter, S. (1982). An evolutionary theory of economic change. Boston: Harvard University Press.

Nerur, S., Rasheed, A., \& Natarajan, V. (2008). The intellectual structure of the strategic management field: An author co-citation analysis. Strategic Management Journal, 29(3), 319-336.

Pablo, E. (2009). Determinants of cross-border M\&As in Latin America. Journal of Business Research, 62(9), 861-867.

Paine, F., \& Power, D. (1984). Merger strategy: An examination of Drucker's five rules for success full acquisitions. Strategic Management Journal, 5(2), 99-100.

Parsons, R., \& Baumgartner, J. (1970). Anatomy of a merger: How to sell your company. Upper Saddle River: Prentice-Hall.

Peng, M. (2012). The global strategy of emerging multinationals from China. Global Strategy Journal, 2(2), 97-107.

Peng, M., Sun, S., Pinkham, B., \& Chen, H. (2009). The institution-based view as a third leg for a strategy tripod. Academy of Management Perspectives, 23(3), 63-81.

Peng, M., \& Zhou, J. (2006). Most cited articles and authors in global strategy research. Journal of International Management, 12(4), 490-508.

Penrose, E. (1959). The theory of the growth of the firm. Oxford: Oxford University Press.

Pfeffer, J., \& Salancik, R. (1978). The external control of organizations: A resource dependence perspective. New York: Harper and Row.
Phelan, S., Ferreira, M., \& Salvador, R. (2002). The first twenty years of the Strategic Management Journal. Strategic Management Journal, 23(12), 1161-1168.

Podsakoff, P., MacKenzie, S., Podsakoff, N., \& Bacharach, D. (2008). Scholarly influence in the field of management: A bibliometric analysis of the determinants of university and author impact in the management literature in the past quarter century. Journal of Management, 34(4), 641-720.

Porter, M. (1980). Competitive strategy: Techniques for analyzing industries and competitors New York: Free Press.

Porter, M. (1985). Competitive Advantage: Creating and sustaining superior performance. New York: Free Press.

Porter, M. (1987). From competitive advantage to corporate strategy. Harvard Business Review, 65(3), 43-59.

Ramos-Rodriguez, A., \& Ruiz-Navarro, J. (2004). Changes in the intellectual structure of strategic management research: A bibliometric study of the Strategic Management Journal, 1980-2000. Strategic Management Journal, 25(10), 981-1004.

Rao, K., \& Sanker, K. (1997). Takeover as a strategy of turnaround. Mumbai: UTI.

Ravenscraft, D., \& Scherer, F. (1987). Mergers, sell-offs and economic efficiency. Washington DC: Brookings Institution.

Rehn, R., \& Kronman, U. (2006). Bibliometric handbook for Karolinska Institutet. Stockholm: Karolinska Institutet University Library Publications.

Roll, R. (1986). The hubris hypothesis of corporate takeovers. The Journal of Business 59(2), 197-216.

Rumelt, P. (1974). Strategy, structure, and economic performance. Cambridge: Harvard University Press.

Salter, M., \& Weinhold, W. (1979). Diversification through acquisition: Strategies for creating economic value. New York: Free Press.

Schäffer, U., Nevries, P., Fikus, C., \& Meyer, M. (2011). Is finance research a "normal science"? A bibliometric study of the structure and development of finance research from 1988 to 2007. Schmalenbach Business Review, 63(2), 189-225.

Schweiger, D., \& DeNisi, A. (1991). Communication with employees following a merger: A longitudinal field experiment. Academy of Management Journal, 34(1), 110-135.

Seth, A. (1990a). Value creation in acquisitions: A reexamination of performance issues. Strategic Management Journal, 11(2), 99-115.

Seth, A. (1990b). Sources of value creation in acquisitions: An empirical investigation Strategic Management Journal, 11(6), 431-446.

Seth, A., Song, K., \& Pettit, R. (2000). Synergy, managerialism or hubris? An empirical examination of motives for foreign acquisitions of U.S. firms. Journal of Internationa Business Studies, 31(3), 387-405.

Shafique, M. (2013). Thinking inside the box? Intellectual structure of the knowledge base of innovation research (1988-2008). Strategic Management Journal, 34(1), 62-93.

Shelton, L. (1988). Strategic business fits and corporate acquisition: Empirical evidence. Strategic Management Journal, 9(3), 279-287.

Singh, H., \& Montgomery, C. (1987). Corporate acquisitions strategies and economic performance. Strategic Management Journal, 8(4), 377-386.

Sirower, M. (1997). The synergy trap: How companies lose the acquisition game. New York: Free Press.

Smith, L. (1981). Citation analysis. Library Trends, 30(1), 83-106.

Tahai, A., \& Meyer, M. (1999). A revealed preference study of management journals' direct influences. Strategic Management Journal, 20(3), 279-296.

Trautwein, F. (1990). Merger motives and merger prescriptions. Strategic Management Journal, 11(4), 283-295.

Vermeulen, E., \& Barkema, H. (2001). Learning through acquisitions. Academy of Management Journal, 44(3), 457-476.

Walsh, J. (1988). Top management turnover following mergers and acquisitions. Strategic Management Journal, 9(2), 173-183.

Wan, W., \& Yiu, D. (2009). From crisis to opportunity: Environmental jolt, corporate acquisitions, and firm performance. Strategic Management Journal, 30(7) 791-801.

Wernerfelt, B. (1984). A resource-based view of the firm. Strategic Management Journal, 5(2), 171-180.

White, D., \& McCain, K. (1998). Visualizing a discipline: An author co-citation analysis of information science, 1972-1995. Journal of the American Society for Information Science, 49(4), 327-355.

Willett, P. (2007). A bibliometric analysis of the Journal of Molecular Graphics and Modelling. Journal of Molecular Graphics and Modelling, 26(3), 602-606.

Williamson, O. (1975). Markets and hierarchies. New York: Free Press.

Yip, G. (1982). Diversification entry: Internal development versus acquisition. Strategic Management Journal, 3(4), 331-345.

Ziman, J. (1968). Public knowledge: An essay concerning the social dimension of science. Cambridge: Cambridge University Press. 